Article

\title{
On the Morphodynamic Alterations around Bridge Piers under the Influence of Instream Mining
}

\author{
Abhijit D. Lade ${ }^{1}$, Vishal Deshpande ${ }^{2}$, Bimlesh Kumar ${ }^{1, * \mathbb{D}}$ and Giuseppe Oliveto ${ }^{3}$ (D) \\ 1 Department of Civil Engineering, Indian Institute of Technology, Guwahati 781039, India \\ 2 Department of Civil and Environmental Engineering, Indian Institute of Technology Patna, \\ Bihar 801103, India \\ 3 School of Engineering, University of Basilicata, Viale dell'Ateneo Lucano, 10, 85100 Potenza, Italy \\ * Correspondence: bimk@iitg.ac.in; Tel.: +91-361-2582420
}

Received: 27 June 2019; Accepted: 9 August 2019; Published: 13 August 2019

\begin{abstract}
Sand mining in an active alluvial channel can compromise the streambed stability of the hydraulic structures nearby. This experimental study is aimed at investigating the effects of rectangular mining pit on the morphodynamics around circular tandem piers in a movable bed. A rectangular pit is excavated upstream of two circular piers embedded in the sand-bed in a tandem arrangement. The results are then compared to a case having only the piers without any mining pit. Turbulent stresses and mean velocities in the near-bed region rise significantly at the upstream region of the piers in the presence of a pit. Also, stronger flow reversal and horseshoe vortices have been detected at the base of the pier front. Due to these alterations in the nature of turbulence, erosion of channel beds upstream of the piers, increased scour depths, scour volume, and lateral erosion of the scour hole have been observed. Dynamic evolution of the local scour at various time scales has been studied using a wavelet cross-correlation method. Spatial evolution of local scour is found to be faster when a pit is excavated in the channel. Thus, mining activities near the piers can lead to significant changes in the flow-field, causing excessive scour around piers.
\end{abstract}

Keywords: sediment mining; local scour; turbulent stresses; wavelet analysis

\section{Introduction}

Excavation of riverbeds is one of the major sources of fine and coarse aggregates required for the construction industry. The adverse impacts of sand mining on the environment and ecology are well established [1]. Geomorphic changes due to such mining activities in the alluvial stream are also significant and can propagate to very large distances from the mining zone. This poses a threat to the streambed stability around the hydraulic structures, such as bridges and buried pipelines present in the vicinity of such mining zones. Several case studies have reported undermining of bridge piers, bed lowering, etc., due to mining activities [1,2].

In order to study the effects of sand mining in alluvial streams, many researchers have treated this phenomenon similar to a pit excavation in an active channel. Lee et al. [3] presented regression equations for the migration speed of a rectangular pit based on experimental studies. They observed channel degradation in the upstream as well as in the downstream locations of the pit. Gill [4] theoretically studied the hydrodynamic behavior of trapezoidal mining pits excavated in an erodible channel under quasi-steady-flow. He observed partial filling of the pits with time and progression of pits along the downstream. Cao and Pender [5] provided a 2D numerical framework to predict the hydrodynamics of alluvial rivers subjected to interactive sediment mining. The 2D model predicted bed lowering in the downstream side of the mining region. Chen et al. [6] studied the impact of gravel mining on Rio Salado (Salt River) in Arizona, using a Center for Computational Hydroscience and 
Engineering (CCHE2D) model. Severe alteration in the flow field around the pit, as well as erosion on both sides of the pit, was observed in the case of 500-year flood discharge. Impacts of a 10.0-m deep mining pit in the same river was studied by Chen and Liu [7] using a one Dimensional Hydrologic Engineering Center River Analysis Systems (1D HEC-RAS) model as well as a Dimensional Hydrologic Engineering Center River Analysis Systems (2D CCHE2D) model. The HEC-RAS model predicted heavy erosion on the upstream side of the pit, while CCHE2D predicted relatively higher downstream erosion. Experiments conducted by Barman et al. [8] reported a rise in the turbulent stresses in the mining pit and at the downstream side of the pit.

It is evident from the existing literature that the excavation of a pit in an alluvial channel can induce erosion in the downstream side. However, very few studies are documented pertaining to the interaction of such flows with the hydraulic structures. Yanmaz and Cicekdag [9] reported streambed instabilities around bridge piers because of pit excavation on the upstream side. Flume studies by Qi and Kuai [10] reported an excess scour induced along with local scour around the piers and escalations in the rate of scour in the presence of a mining pit. Qi et al. [11] studied the efficiency of an end sill to attenuate the scouring of piers caused by the existence of a mining pit. Their study reported a decrease in turbulent intensity and shear stress near the pier in the presence of an end sill in a mining-affected channel

Many researchers have experimentally studied the flow and scour around a group of cylinders [12,13]. The turbulent flow characteristics around cylinders in tandem arrangement depend significantly on the spacing between the two cylinders [14,15]. Ataie-Ashtiani and Aslani-Kordkandi [16] studied the turbulence around two tandem piers in a mobile-bed. They found that the wake behind the tandem piers is significantly different from a single pier and turbulence intensities are higher near the downstream pier. Chavan and Kumar [17] studied the effect of seepage on the turbulence around the tandem piers in a mobile bed. They observed stronger flow reversal in the horseshoe vortex region in the presence of downward seepage. However, the nature of turbulence around tandem piers in a dredged channel is not found in the literature.

Comprehensive investigations regarding the effects of mining pit excavation on the nature of turbulence and morphology around bridge piers are still lacking. The present study is an attempt to fill these gaps and provide a better apprehension of these effects. Flume experiments were designed to analyze the alterations in the flow parameters and scour around two circular piers placed in a tandem (inline) arrangement in the presence of a rectangular pit excavated upstream of the piers. The results are compared to a case in which no mining pit was present in the channel. Alterations in flow parameters, such as mean velocity, turbulent stresses, turbulence intensities, as well as the turbulent kinetic energy are analyzed at critical locations around the piers. Streambed alterations, such as scour depth, scour volume, dune crest and bed levels around the piers, are investigated. In addition, to quantify the effect of a pit on the dynamics of local scour, spatial evolution of local scour is studied using wavelet cross-correlation analysis.

\section{Materials and Methods}

A rectangular flume having a length of $17.2 \mathrm{~m}$ and $1.0 \mathrm{~m}$ width was used to conduct experiments (Figure 1). Uniform river sand having a median size $\left(d_{50}\right)$ of $1.1 \mathrm{~mm}$ and geometric standard deviation $\left(\sigma_{g}\right)$ of 1.1 [18] was laid at the bottom throughout the length of the flume to conduct mobile bed experiments. Suspended sediments were not supplied during the experiments. The thickness of the sand bed was kept at $0.21 \mathrm{~m}$ to accommodate the maximum scour depth around the piers and the slope of the flume was 0.0017 . Water was supplied to the channel from an overhead storage tank $(2.8 \mathrm{~m} \times$ $1.5 \mathrm{~m} \times 1.5 \mathrm{~m}$ ). Baffle walls mounted at the entry of the flume aided the smooth entry of the flow into the channel from the upstream side. The depth of the flow was regulated using a tailgate installed at the downstream end of the flume. 


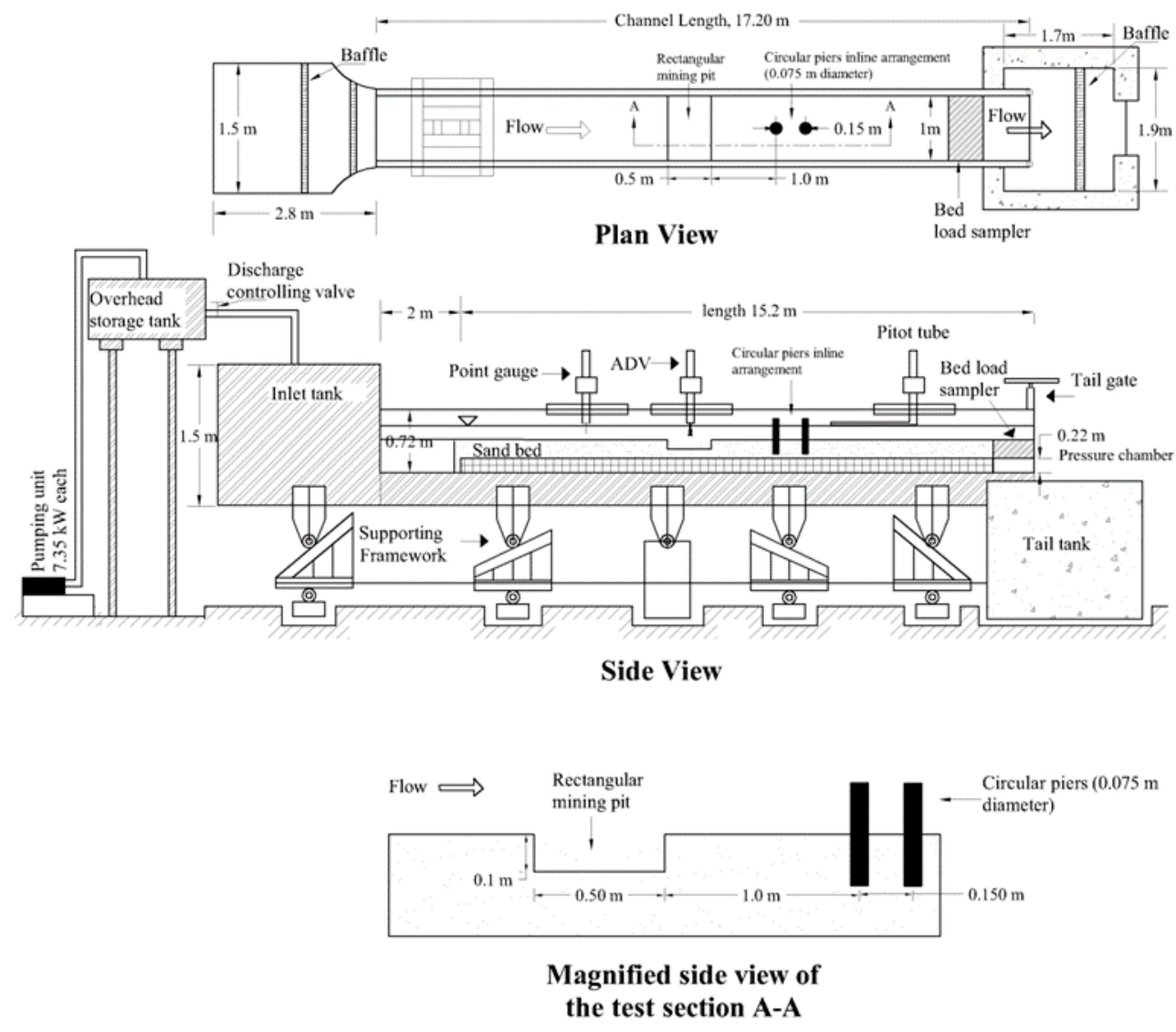

Figure 1. Representational drawings of the experimental setup.

\subsection{Experimental Cases}

Experiments were performed for two cases (Figure 2c,d). For the first case, two circular piers with $75 \mathrm{~mm}$ diameters $(D)$ were embedded carefully in the sand bed in a tandem (inline) arrangement at 6.0-m distance from the downstream end of the flume. Ataie-Ashtiani and Beheshti [19] stated that the proximity interference between the piers can be avoided by keeping the $L / D$ ratio (spacing between the cylinders/diameter of the cylinders) in between 2 and 4 . Therefore, the distance between these two piers $(L)$ was kept to $150 \mathrm{~mm}$, such that $L / D=2.0$. In the second case, in addition to the tandem piers, a rectangular pit was excavated 1.0-m upstream of the pier front to imitate the presence of mining in the channel $[4,10,11,20]$. The pit was excavated before the initiation of flow in the channel so that steady flow conditions were not hampered during the experiment. The length of the pit along the flow direction was $0.5 \mathrm{~m}$, its depth was $0.1 \mathrm{~m}$, and it was excavated for the entire width of the channel, i.e., $1.0 \mathrm{~m}$.

For both cases, the flow was supplied slowly and gradually into the channel such that the sediments did not get washed away. The flow was gradually increased until the required discharge was attained. Muzzammil and Gangadhariah [21] found that the scour depth and horseshoe vortex became independent of the Reynolds number $(\mathrm{Re})$ for $R e>10^{4}$. Therefore, both experiments were conducted at a steady flow discharge of $0.0441 \mathrm{~m}^{3} / \mathrm{s}$ to attain a high Reynolds number $(\operatorname{Re}=49,550)$. The flow depth and undisturbed mean velocity at the upstream location were $0.105 \mathrm{~m}$ and $0.42 \mathrm{~m} / \mathrm{s}$, respectively, for both cases. Sub-critical flow conditions $\left(F_{r}=0.41\right)$ were maintained for both cases using the downstream tail gate. For the no pit case, clear water conditions prevailed in the upstream area of the pier. In the case of the mining pit, erosion was observed at the edges of the pit and at its downstream side, hence live-bed conditions prevailed around the pier. The pier diameter was kept smaller than $10 \%$ of the width of the flume to eliminate the sidewall effects [22]. The ratio of pier diameter to mean sediment size $\left(D / d_{50}\right)$ was greater than 50 to ensure that the scour depth was not 
affected by the coarseness of the sediments [22]. Since the prime focus of the study was to explore the effect of a mining pit on the scour characteristics around the piers, the experimental conditions were maintained in such a way that other parameters, such as $R e, d_{50}$, etc., did not have a significant effect on the scour depth.

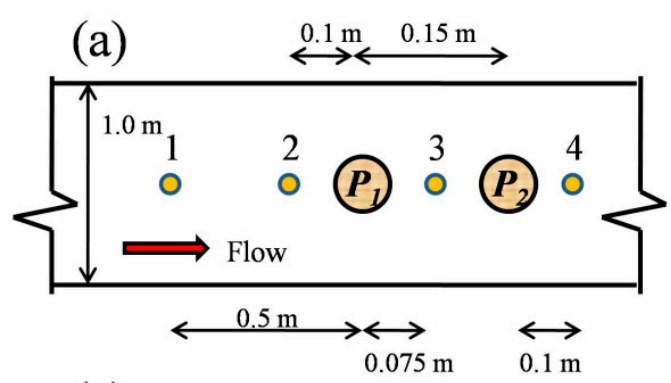

(c)

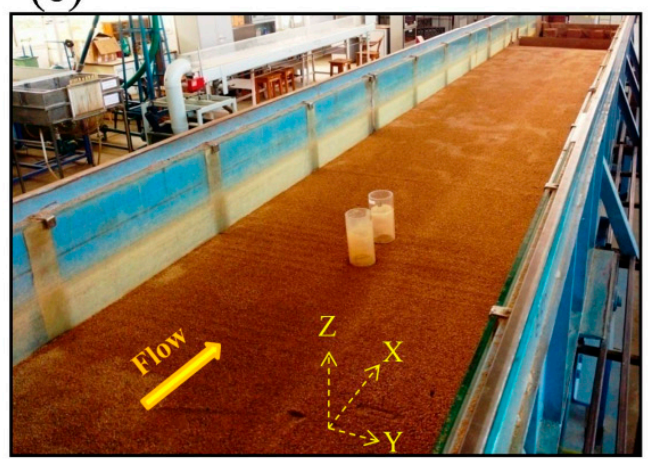

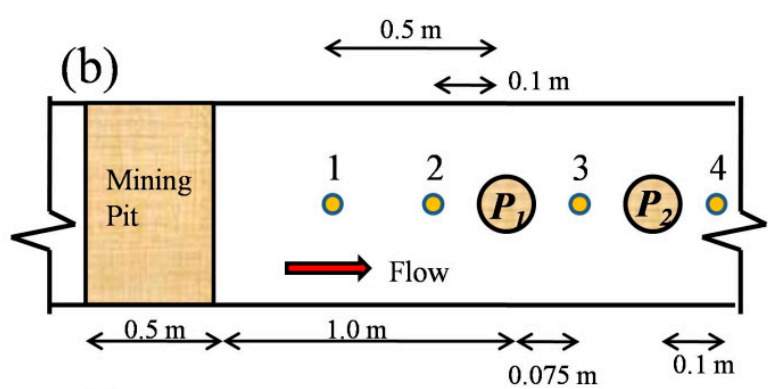

(d)

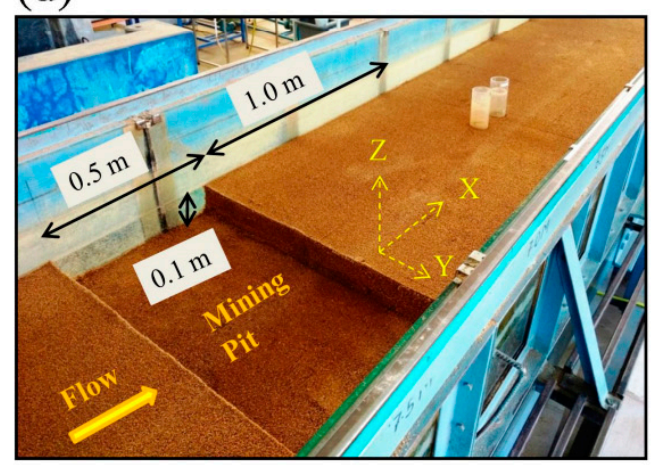

Figure 2. Schematic plan view of data recording locations for: (a) Case A, no pit; (b) Case B, with pit. Snapshots of experimental cases: (c) Case 1, no pit; (d) Case 2, with pit.

\subsection{Data Collection}

Local scour is initiated and simultaneously the downstream edge of the pit also starts to erode rapidly (for the experiment with a pit excavated in the channel bed) as soon as the water passes over the pit and flows around the piers. The upstream edge of the pit deformed until it attained a stable slope. At the end of the experiment, it was found to be nearly equal to the angle of repose of the sand. The downstream edge and the streambed in between the pit and the piers eroded very rapidly at the start of the experiment. Within $2 \mathrm{~h}$ from the initiation of flow, the downstream edge of the pit was smoothly flattened by the flow, and sediment movement in the downstream side of the pit was minimal. However, local scour around the piers continued to occur until the equilibrium scour depth was reached after about $12 \mathrm{~h}$ for both cases. Velocity measurements were recorded as soon as the equilibrium scour was reached, i.e., the scour depth did not change more than $1 \mathrm{~mm}$ in $3 \mathrm{~h}$ [23]. A Seatek(B)ultrasonic ranging system was used to continuously record the scour depth. The experiments were continued until velocity data at all the measurement locations were collected. A Vectrino+ model Acoustic Doppler Velocimeter (ADV) manufactured by Nortek ${ }^{\circledR}$ was used to record the 3-dimensional instantaneous velocities. A 4-beam downward-looking probe was used with a fixed stem, having a sampling frequency up to $200 \mathrm{~Hz}$. At any point in the flow, instantaneous velocity components in the streamwise $(X)$, transverse $(Y)$, and vertical $(Z)$ directions are denoted by $u, v$, and $w$, respectively, and fluctuating components are denoted by $u^{\prime}, v^{\prime}$, and $w^{\prime}$, respectively. Velocity data was recorded at a sampling frequency of $100 \mathrm{~Hz}$ for $180 \mathrm{~s}$ and about 18,000 samples were collected at every point. The height of the cylindrical sampling volume was kept at $1 \mathrm{~mm}$ in the near-bed region and $4 \mathrm{~mm}$ above it. Inside the scour hole, i.e., below $z / h \sim 0.2$, the velocity data with a signal to noise (SNR) ratio of more than 10 and correlation above 65\% were considered as having high noise. Above this depth, data with SNR > 15 and correlation $>70 \%$ were considered. 
Velocity measurements were recorded along the depth (Z-axis) at 4 critical locations along the centerline of the flume (Figure 2a,b). Location 1 was $0.5-\mathrm{m}$ upstream from the center of the pier front. It represents the location where flow approaches the piers after passing over the mining pit. Location 2 was $0.1-\mathrm{m}$ upstream of the center of the pier front within the scour hole, representing the region of the horseshoe vortex. Location 3 was in the center of both the piers, and Location 4 was $0.1-\mathrm{m}$ downstream of the rear pier. The adjustment length required to achieve flow uniformity was estimated to be about $3.0 \mathrm{~m}$ [24]. The zone of the flume utilized for the experiment started about $8.0 \mathrm{~m}$ from the upstream entry of the channel (i.e., $>3.0 \mathrm{~m}$ ) to ensure a fully developed flow in the experiment and ended about $5.0 \mathrm{~m}$ prior to the downstream end of the flume to prevent exit disturbances. The raw velocity data was contaminated with spikes, therefore it had to be filtered before analysis. Spike removal was done by acceleration threshold method [25]. The acceleration threshold value adopted was between 1 to 1.5-times the gravitational acceleration [26], for which the inertial sub-range of the velocity power spectra follows Kolmogorov's $-5 / 3$ law (Figure 3). The comparative results of turbulent flow parameters for both cases are presented in Section 3.1.

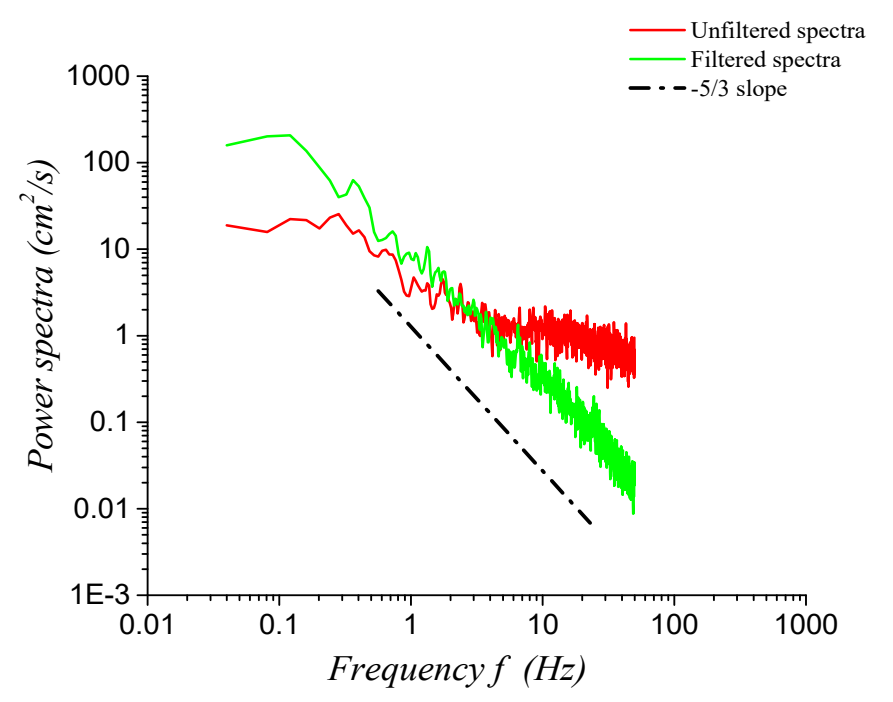

Figure 3. Power spectra of raw as well as filtered velocity time series.

An ultrasonic ranging system (Seatek ${ }^{\circledR}$ make 8 transducer $1.0 \mathrm{~cm}$ diameter model) was installed to continuously record the scour depth upstream and downstream of the pier front (i.e., at Locations 2 and 3). The bed level changes at these locations were recorded at a temporal resolution of $0.5 \mathrm{~s}$. At the end of each experiment, water was carefully drained out and the bed levels around both the piers were manually recorded with a digital point gauge having a count of at least $0.01 \mathrm{~mm}$. Contour plots of morphology were generated using these recordings. Also, the bed elevation time series recorded at Locations 2 and 3 were used to estimate the celerity of scour depth at various time scales by cross-correlation analysis. Results on these effects of a mining pit on the morphological features around the piers, as well as the celerity of scour depth, are shown in Section 3.2.

\section{Results and Discussion}

\subsection{Time Averaged Flow Field}

For both test cases, mean flow parameters, such as mean streamwise velocity, turbulent stresses, and turbulent kinetic energy, were calculated from filtered Acoustic Doppler Velocimeter (ADV) data at Locations 1, 2,3, and 4 . The comparative profiles of these quantities along the normalized depth $z / h$ are presented in this section. 
Mean flow velocities $\bar{u}$ and $\bar{w}$ in streamwise and vertical directions are calculated as:

$$
\begin{aligned}
& \bar{u}=\frac{1}{n} \sum_{i=1}^{n} u_{i} \\
& \bar{w}=\frac{1}{n} \sum_{i=1}^{n} w_{i}
\end{aligned}
$$

where $n$ is the total number of samples. Streamwise velocity profiles at Locations 1, 2, 3, and 4 are shown in Figure 4.
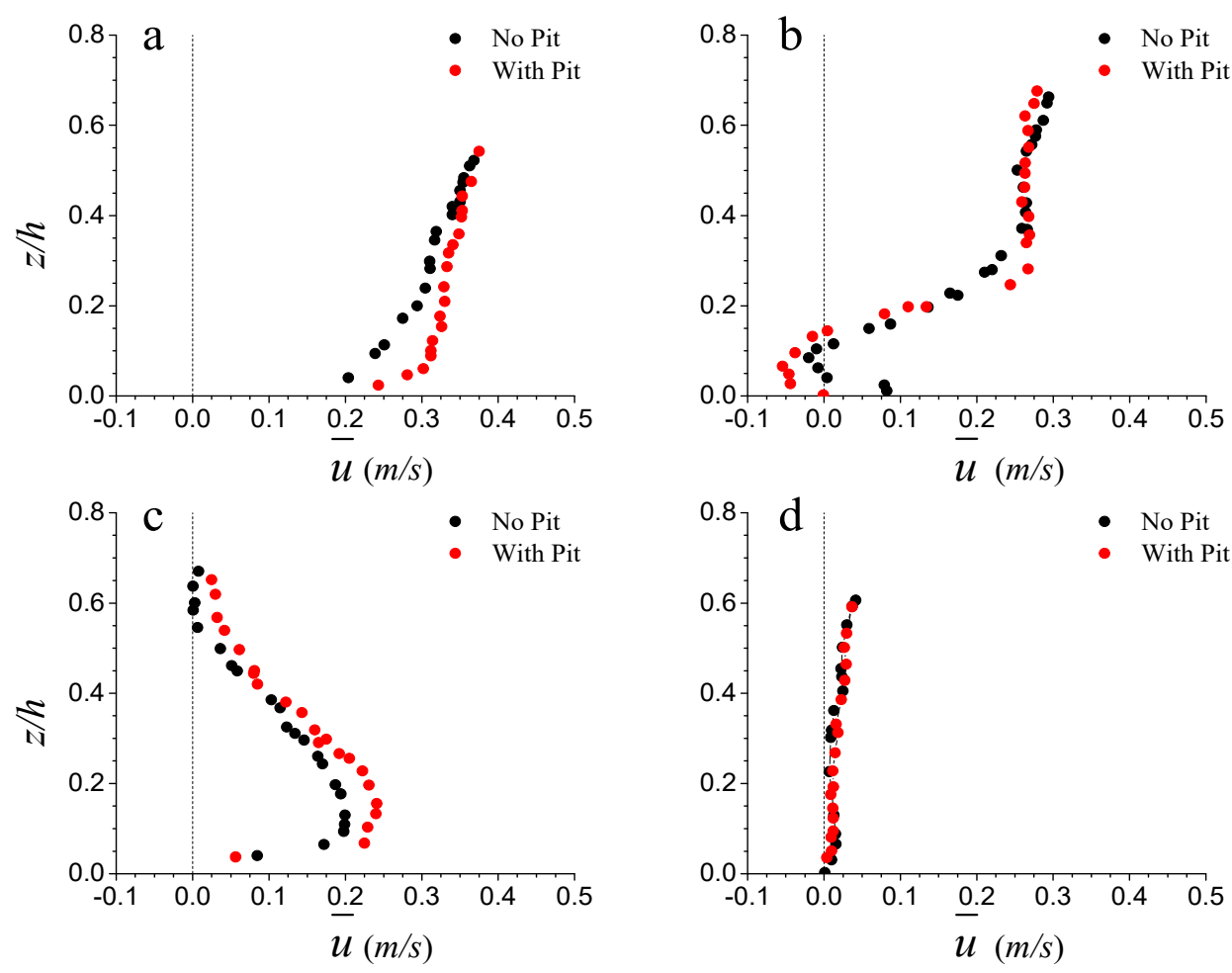

Figure 4. Streamwise mean velocity profiles at: (a) Location 1, (b) Location 2, (c) Location 3, and (d) Location 4.

Figure 4 a represents a region at which the flow is moving towards the piers after passing over the pit (Location 1). At this location, the mean velocity in the near-bed zone (below $z / h \sim 0.2$ ) is $\sim 15 \%$ higher compared to the no pit case. As the flow strikes the pier front $\left(P_{1}\right)$, it is suddenly obstructed by the pier causing stagnation. Stagnation causes a pressure gradient along the depth, and hence the flow moves in the downward direction along the pier. In the near-bed region, flow reversal takes place and a horseshoe vortex is formed. This vortex at the base of the pier front picks up sediments along with it and causes erosion. Scour depth is directly proportional to the strength of this horseshoe vortex. Close observation of Figure $4 \mathrm{~b}$ reveals that in the presence of a mining pit, stronger flow reversal occurs with higher negative velocities at the base of the pier front $\left(P_{1}\right)$. As a result of these higher negative velocities, a stronger horseshoe vortex is formed [27]. Therefore, excavation of a mining pit in the channel leads to greater scour depth and higher volume of sediment extraction at the base of the pier front. The nature of the velocity profiles along the depth for both cases at Location 2 is in agreement with previous studies $[17,28]$. In the central regions of both piers, mean velocities are higher near the bed up to $z / h \sim 0.3$, and above this depth, velocities drop significantly for both experimental cases (Figure $4 \mathrm{c}$ ). In the presence of a pit, there is an overall rise of about $25 \%$ in the mean velocity in this region (Location 3 ). Behind the rear pier $\left(P_{2}\right)$, i.e., at Location 4 (Figure $4 \mathrm{~d}$ ), the streamwise velocities 
are extremely low, indicating flow separation, which is in agreement with the existing literature [15]. The mean velocity profiles in this region are similar for both experimental cases.

Reynolds shear stresses are generated on a plane parallel to the flow direction (plane $X-Y$ ) around the piers, due to the transport momentum across this plane. The streamwise Reynolds Shear Stress (RSS) in the $X-Y$ plane has been calculated by:

$$
\begin{gathered}
\tau_{Z-X}=-\rho \overline{u^{\prime} w^{\prime}} \\
\overline{u^{\prime} w^{\prime}}=\frac{1}{n} \sum_{i=1}^{n}(u-\bar{u})(w-\bar{w})
\end{gathered}
$$

The RSS profiles at Locations 1, 2, 3, and 4 are plotted in Figure 5.
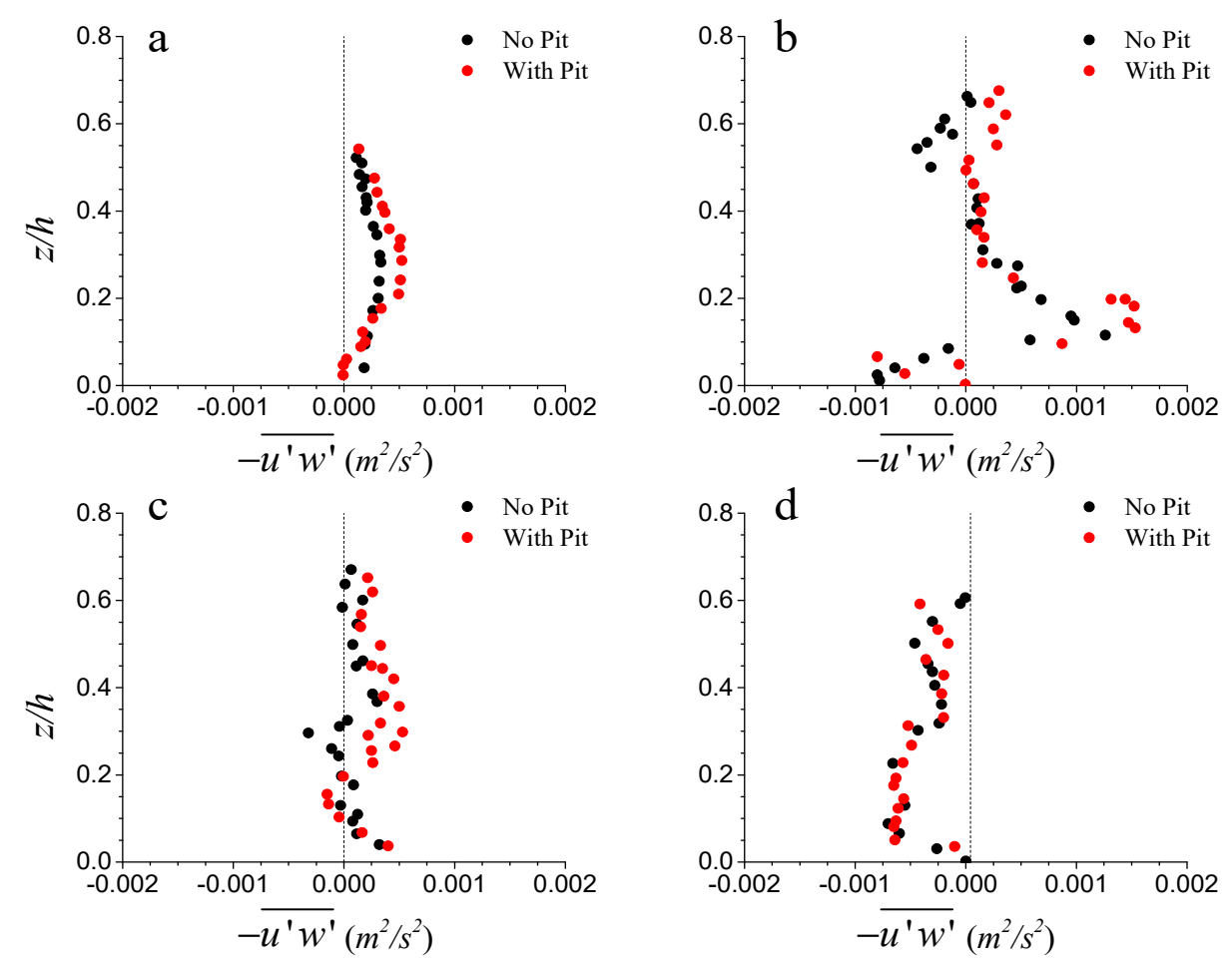

Figure 5. Streamwise Reynolds Shear Stress profiles at (a) Location-\# 1, (b) Location 2, (c) Location 3 , and (d) Location 4.

Excavation of a mining pit generates additional turbulence in the flow when it passes over the pit. Figure 5a indicates that the peak RSS of the flow approaching the pier after passing over the pit is about 1.5-times higher than the no pit case. He horseshoe vortex zone (from the bed level to $z / h \sim 0.25$ ) formed in the presence of a mining pit possesses about $20 \%$ more RSS than the no pit case (Figure $5 \mathrm{~b}$ ). At this location, RSS in the down-flow region (above $z / h \sim 0.25$ ) is also slightly greater in the presence of a pit. An escalation in RSS values ( 15\%) has also been observed in between the two piers (Figure $5 \mathrm{c}$ ) because of pit excavation. Behind the rear pier (Figure $5 d$ ), the contribution of inward and outward interaction towards the production of RSS is greater than sweep and ejection events; hence, the RSS profile is negative throughout the depth for both experimental cases. However, the presence of a mining pit does not cause any significant change in the RSS magnitudes in this region of flow. The RSS variation along the depth for both cases is found, similar to the previous literature [16].

Reynolds Normal Stress (RNS) or turbulence intensities in the streamwise, transverse, and vertical directions are given by:

$$
\sigma_{u}=\sqrt{\left(\overline{u^{\prime} u^{\prime}}\right)}
$$




$$
\begin{gathered}
\sigma_{v}=\sqrt{\left(\overline{v^{\prime} v^{\prime}}\right)} \\
\sigma_{w}=\sqrt{\left(\overline{w^{\prime} w^{\prime}}\right)}
\end{gathered}
$$

Streamwise and vertical turbulence intensities are plotted in Figure 6.
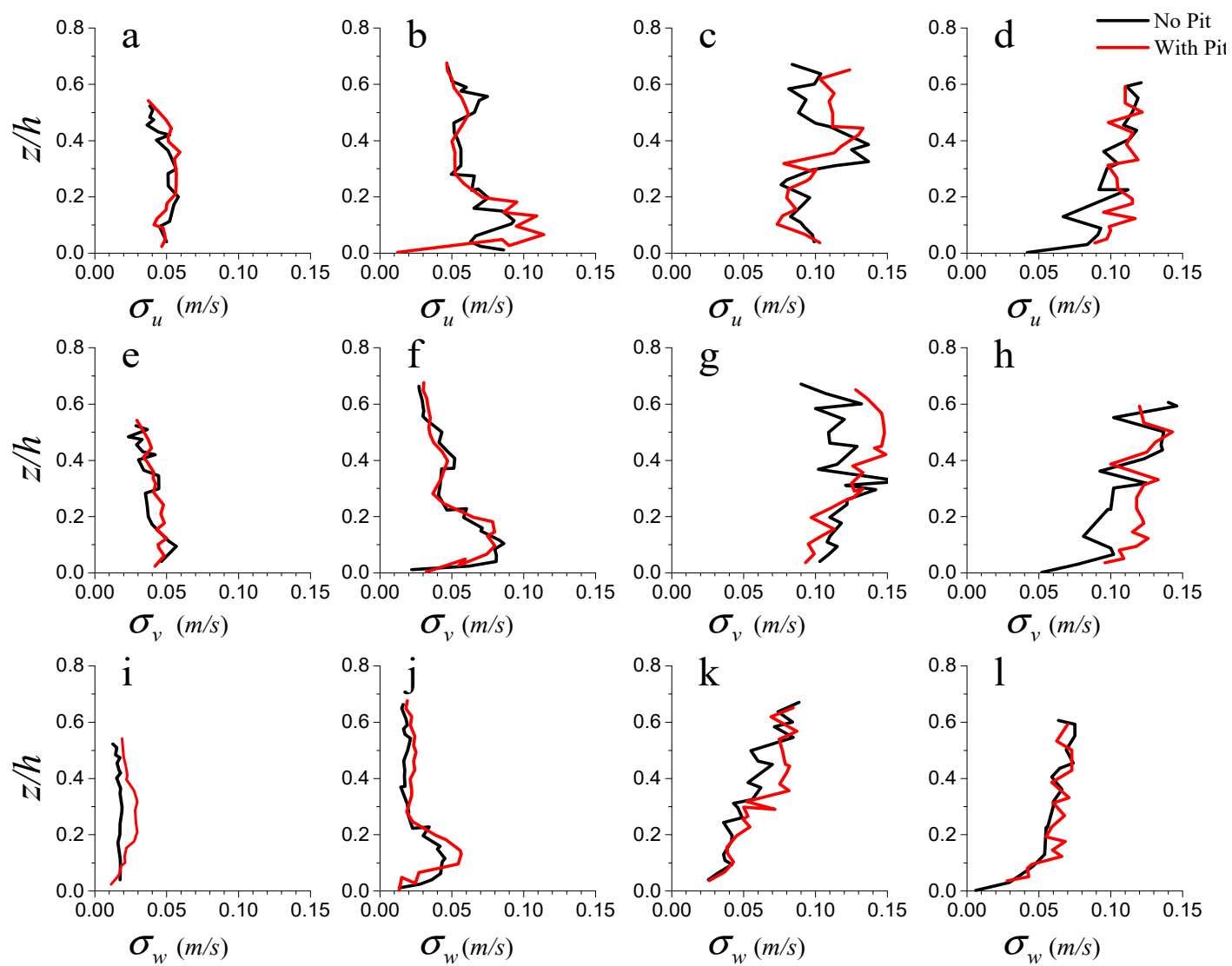

Figure 6. Streamwise turbulence intensity profiles at (a) Location 1, (b) Location 2, (c) Location 3, and (d) Location 4. Transverse turbulence intensity profiles at (e) Location 1, (f) Location 2, (g) Location 3, and (h) Location 4 . Vertical turbulence intensity profiles at (i) Location 1, (j) Location 2, (k) Location 3 , and (1) Location 4.

It is evident from the plots in Figure 6 that after passing over the pit, the flow approaches the piers with significantly higher vertical turbulent intensity $\left(\sigma_{w}\right)$. The horseshoe vortex formed at the base of $P_{1}$ is highly turbulent in the case of a mining pit. In this zone (below $z / h \sim 0.2$ ), mean turbulent intensities in streamwise and vertical directions are about $20 \%$ more than the no pit case (Figure $6 \mathrm{~b}, \mathrm{j})$. The nature of turbulence intensity profiles in this region is similar to the results of Kumar and Kothyari [28]. The flow region between $P_{1}$ and $P_{2}$ is also characterized by a slight increase in $\sigma_{u}$ and $\sigma_{w}$ (Figure $6 \mathrm{c}, \mathrm{k}$ ), because of pit excavation. In this region, the average $\sigma_{v}$ above $z / h \sim 0.3$ increases by $28 \%$ due to pit excavation. Within the separation zone behind $P_{2}$ (Figure $\left.6 \mathrm{~d}, \mathrm{~h}, \mathrm{l}\right), \sigma_{u}$ rises steeply in the near-bed region (up to $z / h \sim 0.3$ ) in the presence of a pit. The average $\sigma_{v}$ in this region is about $30 \%$ more in the presence of a pit. This indicates that the vortex shedding intensity behind $P_{2}$ increases due to pit excavation. Turbulent Kinetic Energy (TKE) is given by

$$
T K E=\frac{1}{2}\left(\overline{u^{\prime 2}}+\overline{v^{\prime 2}}+\overline{w^{\prime 2}}\right)
$$

TKE profiles along normalized depth $(z / h)$ at all four locations are presented in Figure 7. 

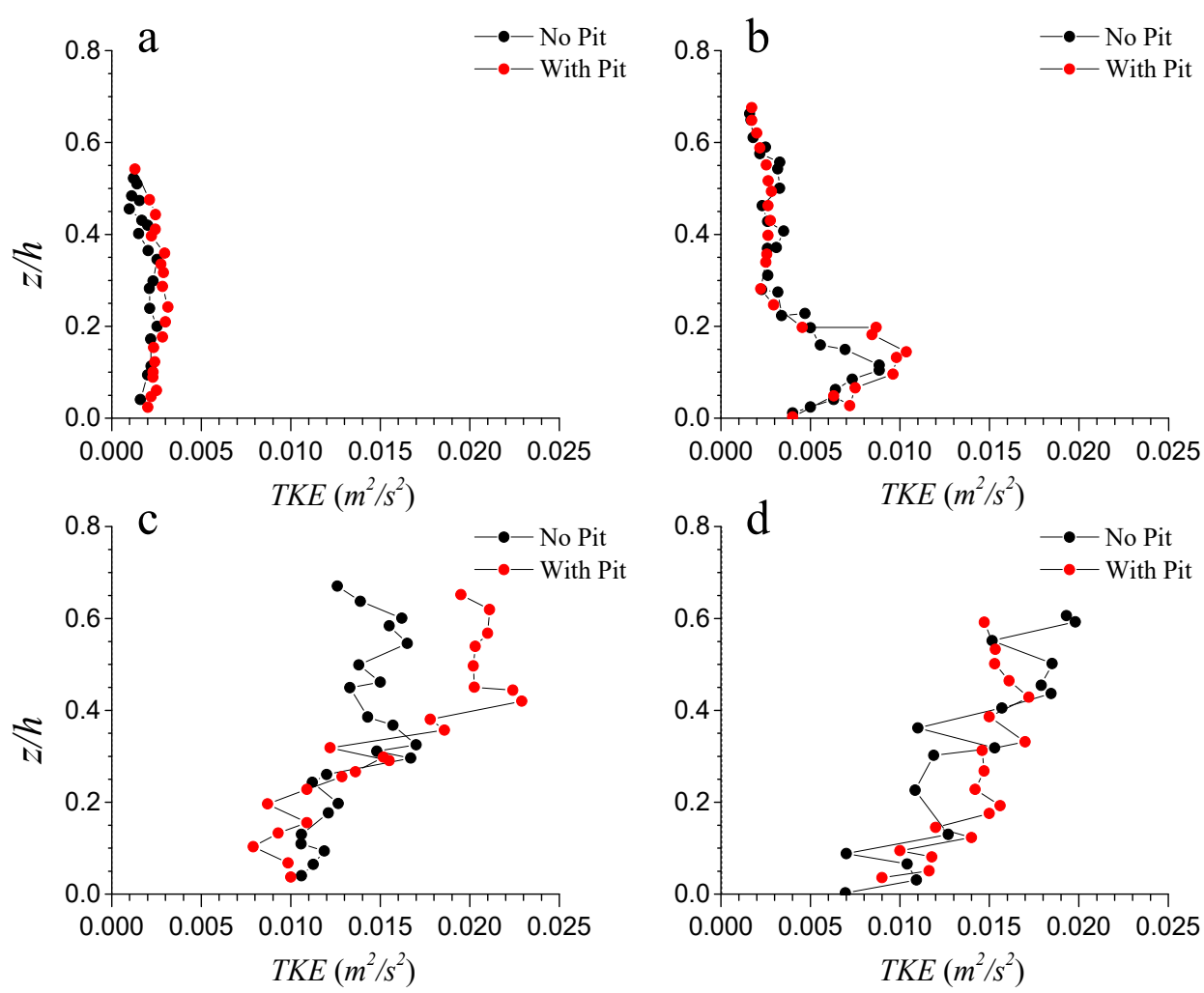

Figure 7. Turbulent kinetic energy (TKE) profiles at (a) Location 1, (b) Location 2, (c) Location 3, and (d) Location 4.

Examination of Figure 7 reveals that TKE is higher in the zone of the horseshoe vortex in front of $P_{1}$, the flow zone between $P_{1}$ and $P_{2}$, and the region behind $P_{2}$, owing to higher velocity fluctuations. The pit acts as a source of turbulence to the flow downstream of the pit, where the piers are present. Therefore, TKE in the zone of the horseshoe vortex is about $15 \%$ higher than the no pit case (Figure $7 \mathrm{~b}$ ). Also, TKE in the flow zone between $P_{1}$ and $P_{2}$ and behind $P_{2}$ is greater than the no pit case.

Bed shear stress $\tau_{0}$ and shear velocity $u_{*}\left(u_{*}=\sqrt{\tau_{0} / \rho}\right)$ were evaluated based on the TKE approach [29] as $\tau_{0}=\left(C_{1} \times \rho \times T K E\right)$, and the calculated values are mentioned in Table 1. Here, $C_{1}$ is a constant and $\rho$ is the mass density of water. Stapleton and Huntley [30] suggested the value of $C_{1}$ as 0.19 for a variety of flows; therefore, we adopted the same value. Pit excavation results in an average rise of $15 \%$ in the bed shear stress around the piers (Table 1 ).

Table 1. Bed shear stress $\left(\tau_{0}\right)$ and shear velocity $\left(u_{*}\right)$ at Locations $1,2,3$, and 4 .

\begin{tabular}{ccccc}
\hline \multirow{2}{*}{ Location } & \multicolumn{2}{c}{ Bed Shear Stress $\boldsymbol{\tau}_{\mathbf{0}}\left(\mathbf{N} / \mathbf{m}^{2}\right)$} & \multicolumn{2}{c}{ Shear Velocity $\mathbf{u} *(\mathbf{m} / \mathbf{s})$} \\
\cline { 2 - 5 } & No Pit & With Pit & No Pit & With Pit \\
\hline Location-1 & 0.304 & 0.418 & 0.0174 & 0.0204 \\
Location-2 & 1.197 & 1.425 & 0.0346 & 0.0377 \\
Location-3 & 2.014 & 1.900 & 0.0449 & 0.0436 \\
Location-4 & 2.075 & 2.261 & 0.0455 & 0.0475 \\
\hline
\end{tabular}

\subsection{Streambed Morphology Around Tandem Piers}

\subsubsection{Morphological Features}

The contour plots of streambed morphology around the tandem piers and the snapshots at the end of the experiments are displayed in Figures 8 and 9, respectively. The statistics of morphological features are provided in Table 2. Initial bed level is considered as the datum. 

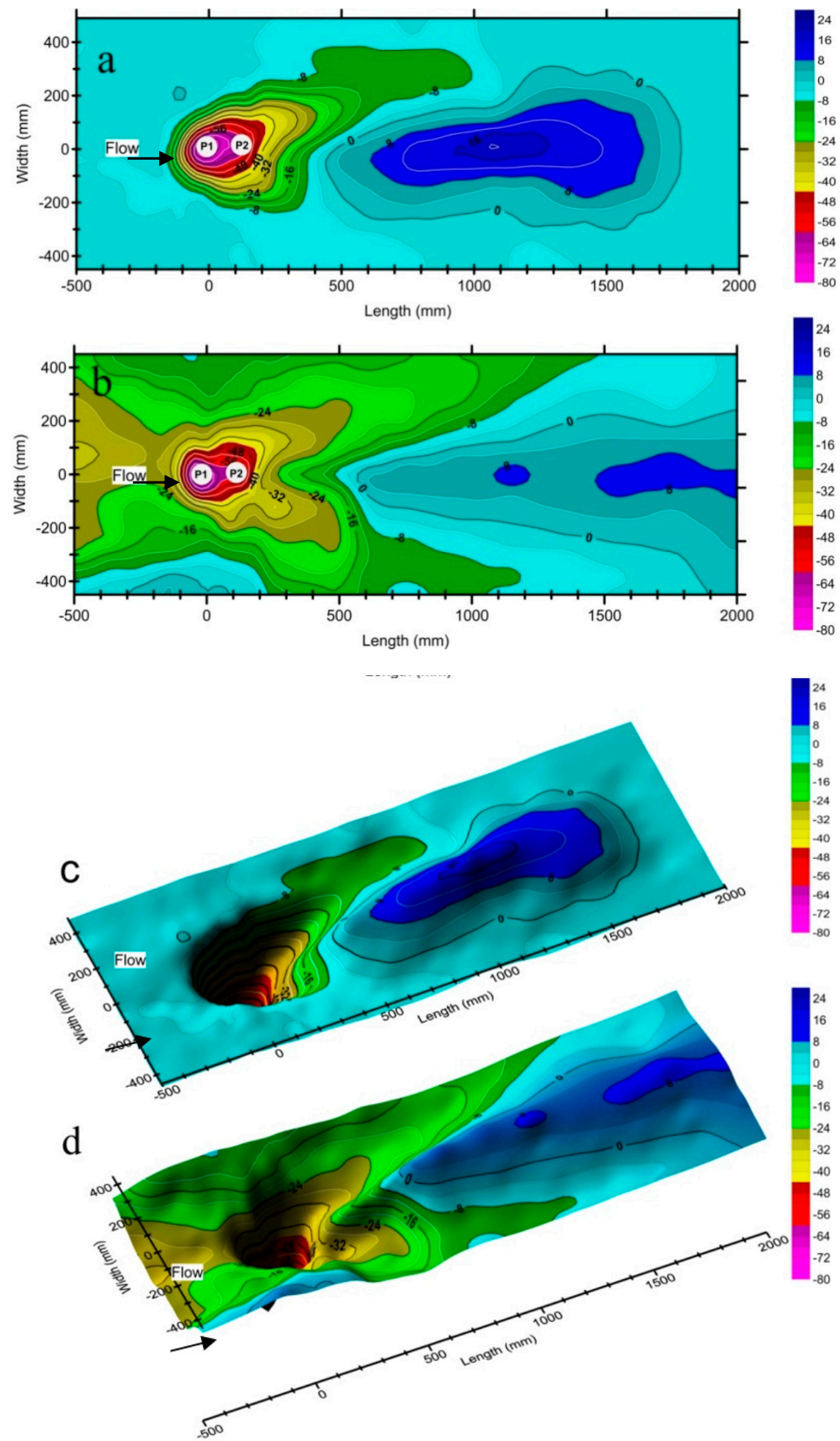

Figure 8. Contour plan of streambed morphology around the piers for (a) no pit and (b) with pit cases, as well as the perspective plots for (c) no pit and (d) with pit cases. 
a

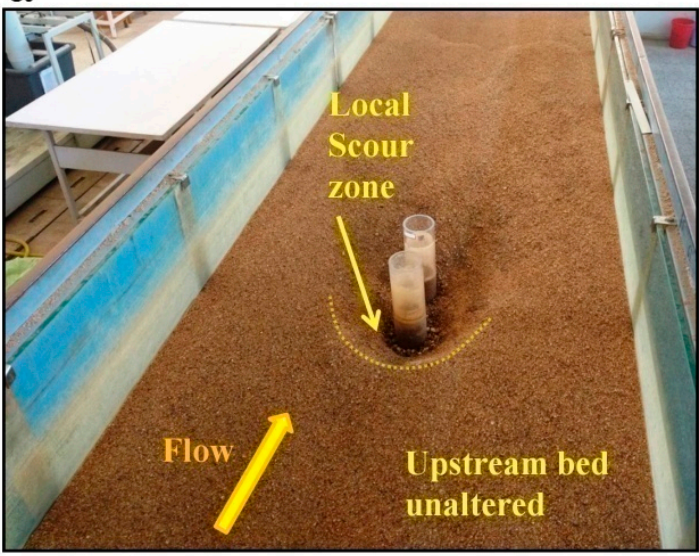

b

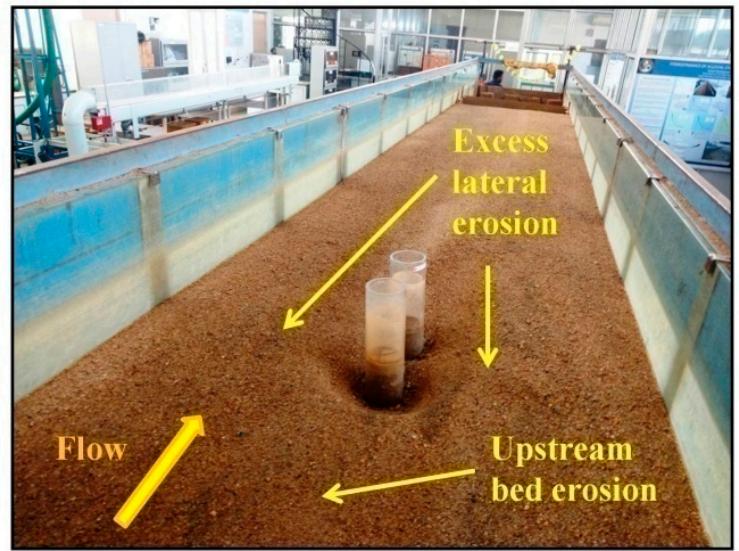

Figure 9. Snapshots showing the morphology around the tandem piers at the end of the experimental run for (a) no pit and (b) with pit cases.

Table 2. Statistics of the morphological features.

\begin{tabular}{cccccc}
\hline Case & $\begin{array}{c}\text { Maximum } \\
\text { Scour Depth at } \\
\boldsymbol{P}_{\mathbf{1}}(\mathbf{m m})\end{array}$ & $\begin{array}{c}\text { Maximum } \\
\text { Scour Depth at } \\
\boldsymbol{P}_{\mathbf{2}} \mathbf{( \mathbf { m m } )}\end{array}$ & $\begin{array}{c}\text { Scour Volume } \\
\left(\mathbf{m m}^{\mathbf{3}}\right)\end{array}$ & $\begin{array}{c}\text { Average } \\
\text { Upstream Bed } \\
\text { Level }(\mathbf{m m})\end{array}$ & $\begin{array}{c}\text { Distance of } \\
\text { Dune Crest } \\
\text { from } \boldsymbol{P}_{\mathbf{1}}(\mathbf{m m})\end{array}$ \\
\hline No Pit & 77.8 & 60.0 & $12,735,436.5$ & -03.0 & 1200 \\
With Pit & 82.0 & 59.5 & $19,678,061.8$ & -25.0 & 1750 \\
\hline
\end{tabular}

For the no pit case (Figure 8a), the flow was initially obstructed by the pier front $\left(P_{1}\right)$ and a down-flow was initiated along $P_{1}$ because of stagnation. The interaction of the down-flow with the main flow in the streamwise direction leads to the formation of horseshoe vortices owing to the reversal of flow occurring at the base of $P_{1}$. These vortices dislodge the sediments at the base of $P_{1}$ causing local scour. The maximum scour depth in front of the pier $P_{1}$ was found to be $77.8 \mathrm{~mm}$ (Figures $8 \mathrm{a}$ and 9a). The flow passed around $P_{1}$ and immediately encountered the rear pier $P_{2}$. As the flow had a high Reynolds number $\left(\operatorname{Re}>10^{4}\right)$ and a $L / D$ ratio of 2.0, wake interference existed between the piers [14]. If the $L / D$ ratio is less than 2, proximity interference exists and the boundary layer does not reattach in between the two piers [14]. Accordingly, in the present case, reattachment of the turbulent boundary layer occurred in the region between both piers. This has been confirmed by positive velocities recorded in this zone. High velocity flow in the near-bed region of $P_{2}$ caused scouring around it. Maximum scour depth in front of the rear pier $P_{2}$ was found to be $60 \mathrm{~mm}$ (Figures $8 \mathrm{a}$ and $9 \mathrm{a}$ ). Flow separation occurred behind the rear pier $P_{2}$ and the wake zone was created. Very low streamwise velocities were observed in this region. Due to this, deposition of sediment occurred along the centerline at the downstream side of $P_{2}$, which leads to the formation of a dune-like structure [17]. The maximum height of the dune was found to be $22 \mathrm{~mm}$ (above the initial bed level) and it was observed at $1200 \mathrm{~mm}$ downstream of $P_{1}$.

In the second experimental case, a rectangular pit was excavated $1.0-\mathrm{m}$ upstream of the pier front, as stated above. After passing over the pit, the flow approaches the piers with higher near-bed velocities, greater bed shear stresses, and increased turbulence intensities compared to the no pit case. The mining pit acts as a source of turbulence generation in the downstream flow. Increased turbulence in the flow caused heavy erosion and lowering of the channel bed upstream of the piers (Figures $8 \mathrm{~b}$ and $9 \mathrm{~b}$ ). An average channel degradation of about $25 \mathrm{~mm}$ was observed in the upstream bed. This spatially accelerating flow struck the pier front $P_{1}$ and a stronger flow reversal occurred at the base of $P_{1}$. This led to the formation of a stronger horseshoe vortex possessing higher turbulent kinetic energy and turbulent stresses than the no pit case. The stronger horseshoe vortex did not allow the incoming sediments to settle in the scour hole. Rather, it continued moving downstream and eroded the lateral 
sides of the scour hole. Deposition was observed further downstream as compared to the no pit case. The maximum scour depth found in this case $(82 \mathrm{~mm})$ was slightly higher than the no pit case. This highly turbulent flow at the base of $P_{1}$ caused excess erosion of the scour hole in the lateral direction and led to greater exposure of both the piers.

The cross-sectional scour profiles at piers $P_{1}$ and $P_{2}$ and the longitudinal bed profile along the centerline of the flow are presented in Figure 10. Close examination of Figure 10 reveals that in the presence of a mining pit, the edges of the scour hole in the lateral direction are shifted further away from the piers. The overall volume of sediments extracted around the piers is about 1.5-times greater than the no pit case (Table 1). The dune crest behind the rear pier $P_{2}$ is shifted further downstream (1750 $\mathrm{mm}$ from $P_{1}$ ) compared to the no pit case $\left(1200 \mathrm{~mm}\right.$ from $\left.P_{1}\right)$.
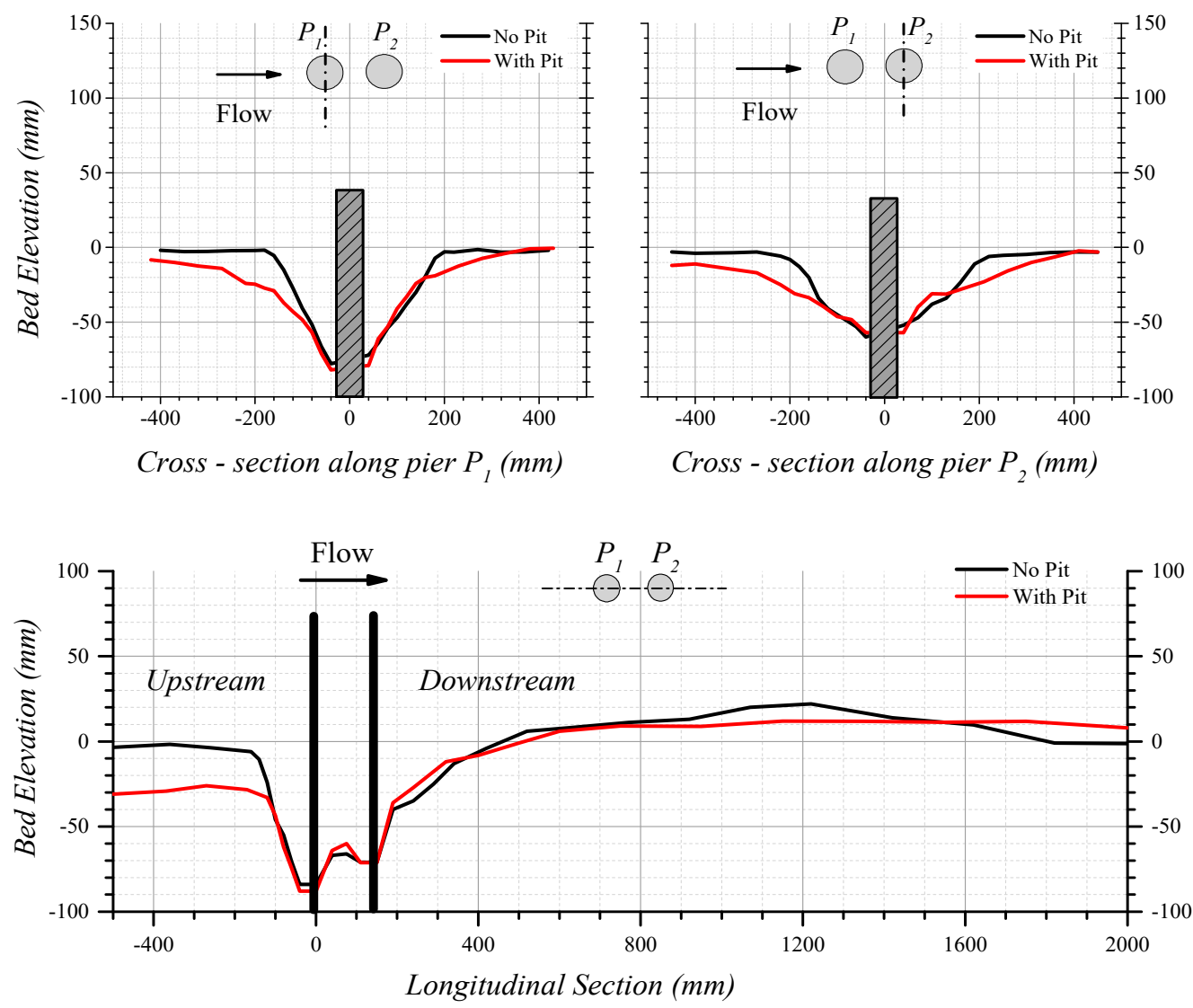

Figure 10. Cross-sections along both the piers and longitudinal section along the centerline.

\subsubsection{Wavelet-Based Statistical Evolution of Local Scour}

The aim of this study is to statistically estimate the spatial evolution of scour depth at various time scales. In order to explore the evolution of local scour in the presence of a mining pit at various time scales, wavelet analysis was employed [31,32]. The statistical speed of spatial evolution of local scour at various time scales was evaluated using cross-correlation analysis of the wavelet coefficients, and the results are presented in the following section.

The temporal progression of local scour was tracked at two fixed locations, i.e., upstream and downstream of the front pier (Location 1 and Location 2, respectively). Firstly, the bed elevation time series at the two tracking locations were recorded. These represented the scour depth (amplitude of the signal) against time. We then transformed each of the signals (bed elevation time series in this case) using a wavelet to obtain a matrix of wavelet coefficients. The matrix has rows equal to the number of time scales that we wanted to study and columns equal to the number of data points in the time series. Thus, we obtained the distribution of amplitude for various time scales along the entire 
length of the signal. Finally, after calculating the wavelet coefficients for both the bed elevation time series, the cross-correlation between the two signals was calculated for all of the time scales. For a particular time scale, maximum cross-correlation in the two signals was obtained. This maximum cross-correlation occurred at a time difference in the two signals and this difference was considered as the lag time. Statistically, this lag represents the time required for the scour depth at that particular time scale to evolve from the pier upstream to the pier downstream. The distance between the two measurement locations was divided with this time lag to obtain the speed of the spatial evolution of scour depth at that particular time scale. The same procedure was repeated for various time scales. Note that the spatial evolution estimated by this method is based on the statistical dependence of the cross-correlation between the wavelet coefficients.

For this analysis, the bed elevations at Locations 2 and 3 (upstream and downstream of $P_{1}$ ), recorded at a temporal resolution of $0.5 \mathrm{~s}$, are utilized. The bed elevations of local scour at $2 \mathrm{~h}, 4 \mathrm{~h}$, and $6 \mathrm{~h}$ are plotted in Figure 11 for both cases.
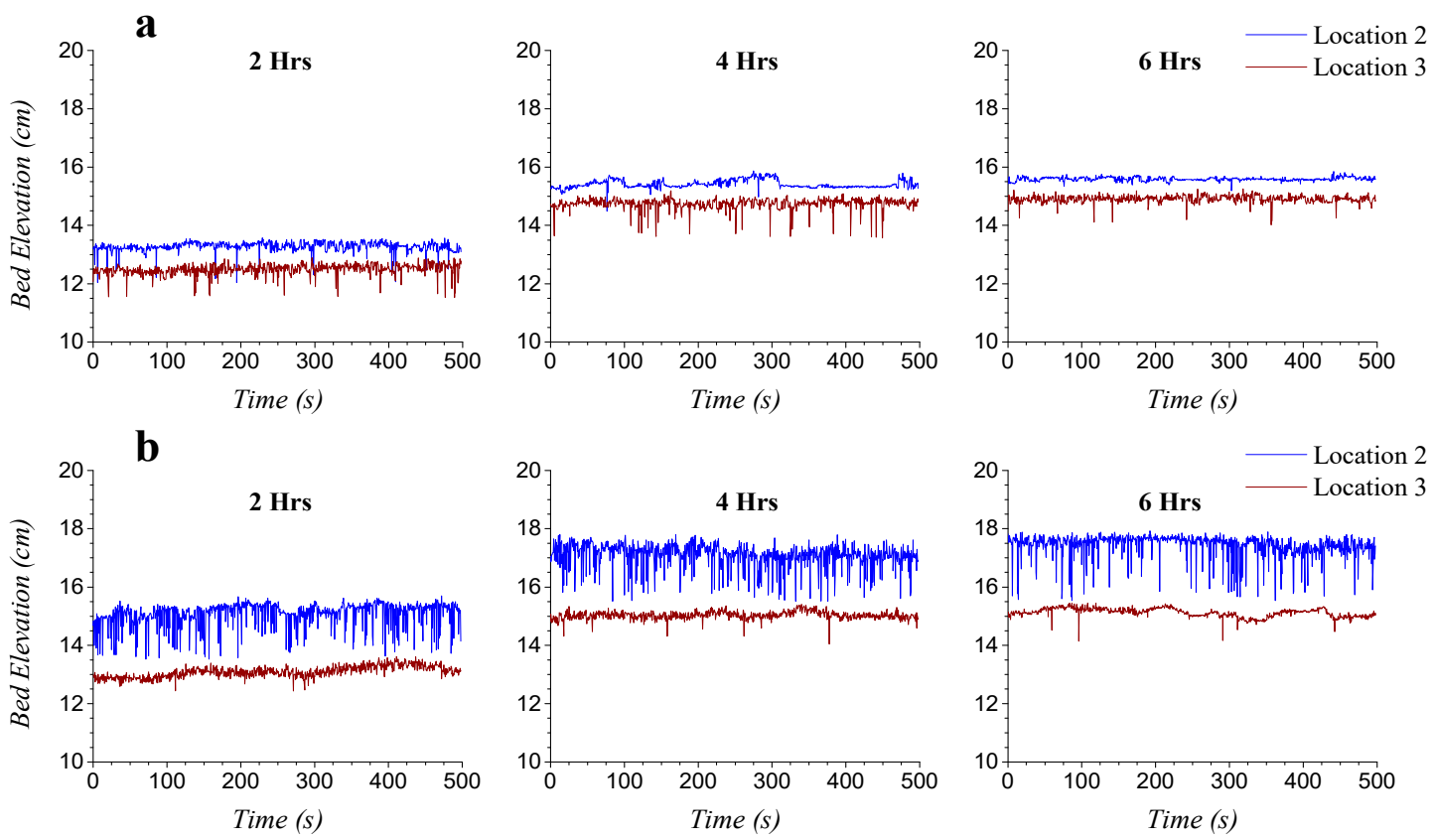

Figure 11. Bed elevation time series of scour depth (upstream and downstream) of $P_{1}$ for (a) no pit and (b) with pit cases.

Careful observation shows that fluctuations in the scour depth are greater in the case of the mining pit. The reason for this lies in the flow alterations in the horseshoe vortex zone in the presence of a pit. The vortex formation at the base of the pier is highly unsteady. For every event of vortex formation, whose primary circulation lies in the $X-Z$ plane, sediments are dislodged from the bed and are suspended for a fraction of time. Depending upon the specific weights of individual sediment particles, some of them are swept downstream, while some again settle down in the scour hole. Movement or settling of the particles depends upon the balance of drag and lift forces acting on the sediment particles and their specific weights. Because of this unsteady movement of bed particles within the scour hole, there are fluctuations in the recordings of bed elevations (Figure 11). Higher fluctuations in the presence of a mining pit is an implicit indication of a higher number of unsteady vortex events, compared to the no pit case.

The spatial evolution of scour at various time scales can be useful in understanding the effect of mining pit local scour around bridge piers. Local scour at the base of the piers is a time-dependent, non-linear phenomenon. Therefore, wavelets are used to transform the bed elevation time series of local scour into multi-scale coefficients. A major advantage of using wavelets is that it provides a matrix of coefficients that are identified by their scale and translation. Hence, the distribution of 
amplitude for a signal can be understood at various scales, as well as translations, as opposed to fast Fourier transform, wherein amplitude distribution only in the frequency domain is obtained and the information across the time domain is lost.

The bed elevation time series at both these locations were treated as discrete signals over the time domain. The bed elevation series upstream and downstream of $P_{1}$ are referred to as two signals, $f_{1}(t)$ and $f_{2}(t)$, respectively. Continuous wavelet transform of a signal $f(t)$ is given by:

$$
W_{f(t)}(a, b)=\int_{-\infty}^{+\infty} f(t) \psi_{a, b}(t) d t
$$

where $\psi_{a, b}$ is a wavelet function, which comes from a mother wavelet $\psi(t)$ post translation and scaling, given by:

$$
\psi_{a, b}(t)=\frac{1}{\sqrt{a}} \psi\left(\frac{t-b}{a}\right) ; \quad a>0 ; \quad b \in R .
$$

Here, $a$ is the scale and $b$ is the translation, i.e., location along the signal; $1 / \sqrt{a}$ is a multiplying factor to normalize the variance [33]. A necessary condition for wavelet transform is that the area under the wavelet function should be zero, i.e., $\int_{-\infty}^{+\infty} \psi(t) d t=0$. A Mexican hat wavelet $\phi(t)$ is used in this study, which has a number of vanishing moments set as 2 . Hence, this wavelet transform acts as a second-order local differencing filter and eliminates the linear trend in the signal along the translation. More details about wavelets can be found in previous literature [34].

$$
\phi(t)=\frac{2}{\sqrt{3}} \pi^{-1 / 4}\left(1-t^{2}\right) e^{-t^{2} / 2}
$$

Thus, the wavelet coefficients for both the bed elevation time series along various scales and translation are obtained by the following expression:

$$
W C(a, b)=\frac{1}{\sqrt{a}} \int_{-\infty}^{+\infty} f(t) \phi\left(\frac{t-b}{a}\right) d t
$$

The wavelet cross-correlation analysis can be useful in assessing the statistical dependence between two signals separated by a spatial distance $S$. After calculating the wavelet coefficients from the above expression, the cross-correlation between two signals was obtained by:

$$
W C C_{f_{1}(t) f_{2}(t)}(a, \Delta t)=\int_{-\infty}^{+\infty} W C_{f 1}(a, b) W C_{f 2}(a, b+\Delta t) d b
$$

Here, $W C_{f 1}(a, b)$ and $W C_{f 2}(a, b+\Delta t)$ are the wavelet coefficients of bed elevation series $f_{1}(t)$ and $f_{2}(t)$, respectively, at scale $a$ and two consecutive locations $b$ and $b+\Delta t$ along the signals. For a particular scale $a$, the lag $\Delta t_{\max }$, which resulted in maximum cross-correlation between the wavelet coefficients of two signals $f_{1}(t)$ and $f_{2}(t)$, was calculated. The speed of spatial evolution of the scour at scale $a$ can be calculated as $V_{c}(a, \Delta t)=S / \Delta t_{\text {max }}$.

For this study, the spatial evolution speed of the local scour at various time scales at $2 \mathrm{~h}, 4 \mathrm{~h}$, and $6 \mathrm{~h}$ from the start of both experiments has been calculated. The spatial evolution speed of local scour at various time scales is provided in Table 3 and plots are presented in Figure 12.

Scour evolution is a dynamic process and spatial evolution (between upstream and downstream of the pier) with the time scale is non-linear (Figure 12b). The spatial evolution at lower time scales is faster and it becomes nearly constant at about $25 \mathrm{~s}$ for the no pit case and $30 \mathrm{~s}$ in the case of the mining pit. Figure $12 \mathrm{~b}$ shows that the spatial evolution of local scour at smaller time scales $(<20 \mathrm{~s})$ is faster in the case of the mining pit. Especially, at the early stage of the run $(2 \mathrm{~h})$, the average speed of spatial scour evolution in the case of the mining pit is found to be maximum $(2.545 \mathrm{~m} / \mathrm{h})$ in comparison to the no pit case $(2.157 \mathrm{~m} / \mathrm{h})$. This indicates that spatial evolution of scour at smaller time scales is faster in 
the case of the mining pit. The spatial scour evolution is about $15 \%$ faster because of the excavation of the mining pit (Table 3).

Table 3. Spatial evolution speed of local scour (between upstream and downstream of the pier) for different time scales.

\begin{tabular}{|c|c|c|c|c|c|c|}
\hline \multirow{3}{*}{ Time Scale (s) } & \multicolumn{6}{|c|}{ Spatial Evolution Speed $(\mathrm{m} / \mathrm{h})$} \\
\hline & \multicolumn{2}{|c|}{$2 \mathrm{~h}$} & \multicolumn{2}{|c|}{$4 \mathrm{~h}$} & \multicolumn{2}{|c|}{$6 \mathrm{~h}$} \\
\hline & No Pit & With Pit & No Pit & With Pit & No Pit & With Pit \\
\hline 1 & 6.641 & 5.405 & 6.084 & 5.758 & 6.696 & 4.300 \\
\hline 2 & 5.198 & 5.029 & 4.886 & 5.228 & 5.098 & 3.929 \\
\hline 3 & 4.455 & 5.129 & 4.728 & 3.777 & 4.119 & 3.903 \\
\hline 4 & 3.740 & 4.953 & 4.589 & 3.567 & 3.016 & 3.423 \\
\hline 5 & 3.307 & 4.690 & 4.611 & 3.516 & 2.938 & 3.380 \\
\hline 6 & 3.471 & 4.122 & 4.331 & 3.070 & 2.582 & 3.439 \\
\hline 7 & 3.354 & 3.412 & 3.727 & 2.850 & 2.428 & 3.386 \\
\hline 8 & 3.194 & 3.060 & 3.182 & 2.841 & 2.435 & 3.714 \\
\hline 9 & 2.993 & 2.760 & 2.866 & 3.050 & 2.457 & 3.541 \\
\hline 10 & 2.981 & 2.575 & 2.732 & 3.007 & 2.289 & 2.966 \\
\hline 11 & 2.896 & 2.462 & 2.471 & 3.015 & 2.204 & 2.492 \\
\hline 12 & 2.619 & 2.411 & 2.330 & 3.020 & 2.153 & 2.226 \\
\hline 13 & 2.391 & 2.403 & 2.269 & 2.759 & 2.005 & 2.067 \\
\hline 14 & 2.217 & 2.434 & 2.270 & 2.614 & 1.874 & 1.997 \\
\hline 15 & 2.075 & 2.494 & 2.313 & 2.544 & 1.759 & 1.957 \\
\hline 16 & 1.953 & 2.567 & 2.131 & 2.517 & 1.659 & 1.929 \\
\hline 17 & 1.865 & 2.663 & 1.901 & 2.550 & 1.577 & 1.916 \\
\hline 18 & 1.799 & 2.755 & 1.716 & 2.412 & 1.508 & 1.894 \\
\hline 19 & 1.733 & 2.807 & 1.565 & 2.279 & 1.448 & 1.856 \\
\hline 20 & 1.681 & 2.704 & 1.445 & 2.185 & 1.395 & 1.811 \\
\hline 21 & 1.630 & 2.541 & 1.350 & 2.107 & 1.346 & 1.762 \\
\hline 22 & 1.589 & 2.357 & 1.277 & 2.056 & 1.304 & 1.715 \\
\hline 23 & 1.546 & 2.185 & 1.219 & 2.015 & 1.263 & 1.673 \\
\hline 24 & 1.504 & 2.040 & 1.175 & 1.974 & 1.223 & 1.628 \\
\hline 25 & 1.460 & 1.922 & 1.143 & 1.927 & 1.185 & 1.587 \\
\hline 26 & 1.413 & 1.827 & 1.119 & 1.871 & 1.148 & 1.546 \\
\hline 27 & 1.376 & 1.755 & 1.102 & 1.819 & 1.114 & 1.507 \\
\hline 28 & 1.331 & 1.698 & 1.091 & 1.756 & 1.081 & 1.476 \\
\hline 29 & 1.293 & 1.652 & 1.085 & 1.688 & 1.051 & 1.449 \\
\hline 30 & 1.259 & 1.618 & 1.084 & 1.620 & 1.025 & 1.426 \\
\hline 31 & 1.226 & 1.590 & 1.084 & 1.552 & 1.000 & 1.407 \\
\hline 32 & 1.195 & 1.567 & 1.087 & 1.490 & 0.978 & 1.391 \\
\hline 33 & 1.173 & 1.553 & 1.092 & 1.435 & 0.960 & 1.382 \\
\hline 34 & 1.153 & 1.543 & 1.098 & 1.388 & 0.944 & 1.376 \\
\hline 35 & 1.135 & 1.533 & 1.103 & 1.347 & 0.930 & 1.372 \\
\hline 36 & 1.118 & 1.525 & 1.108 & 1.309 & 0.917 & 1.368 \\
\hline 37 & 1.103 & 1.520 & 1.111 & 1.276 & 0.907 & 1.364 \\
\hline 38 & 1.086 & 1.517 & 1.111 & 1.246 & 0.900 & 1.362 \\
\hline 39 & 1.074 & 1.510 & 1.112 & 1.220 & 0.891 & 1.357 \\
\hline 40 & 1.064 & 1.507 & 1.109 & 1.193 & 0.885 & 1.357 \\
\hline $\begin{array}{l}\text { Average speed of } \\
\text { spatial evolution }\end{array}$ & 2.157 & 2.545 & 2.120 & 2.371 & 1.817 & 2.141 \\
\hline
\end{tabular}



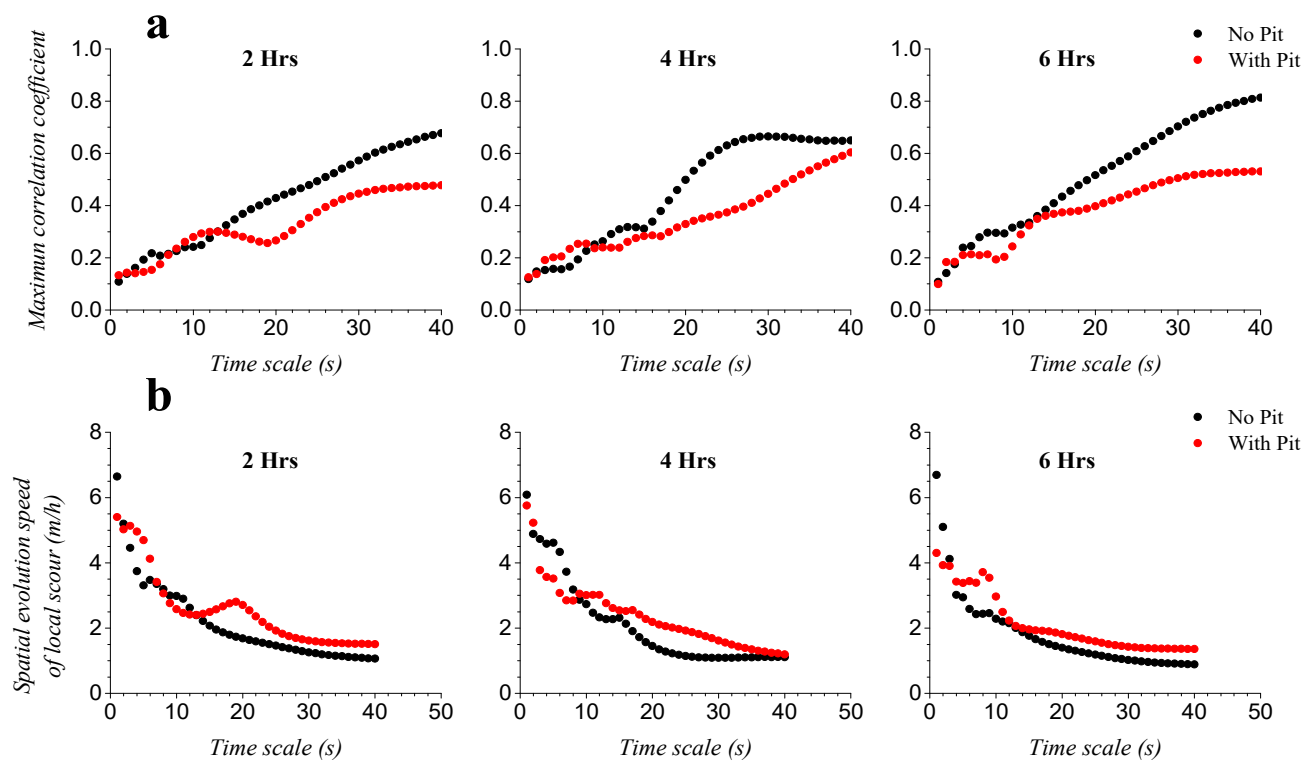

Figure 12. (a) Maximum correlation coefficients between the wavelet-coefficients upstream and downstream of the pier front and (b) spatial evolution speed of local scour at various time scales for both cases.

\section{Concluding Remarks}

Experiments have been performed in an alluvial channel to explore the effects of a mining pit on the morphodynamics around two circular tandem piers present in the downstream side of the pit. The results obtained for flow parameters and streambed morphology were compared with a case where no pit was present upstream of the piers. Key findings of the comparative analysis are given below.

After passing over a pit, the flow approaches the piers with higher mean velocities and increased turbulent stresses. The bed upstream of the piers was subjected to higher bed shear stresses in the presence of an upstream mining pit. Excess erosion and streambed lowering have been observed in this region. The interaction of this incoming flow with the pier front resulted in a stronger reversal zone at the base of the pier. This led to the formation of a horseshoe vortex having higher turbulent kinetic energy and turbulent stresses compared to the no pit case. These alterations in the turbulent characteristics of the flow were responsible for greater scour depth and widening of scour hole on the lateral sides. The spatial evolution of local scour was remarkably faster in the presence of a pit. Excavation of the pit in the channel caused higher exposure of the piers due to lateral erosion of scour hole. Also, the dune crest behind the rear pier was shifted further downstream.

Thus, mining activities on the upstream side of tandem piers cause excess erosion of streambeds around the piers, as well the local scour region. These alterations in the flow field and morphology around the piers caused by the mining activities can endanger the stability of such hydraulic structures.

Author Contributions: Conceptualization, A.D.L. and B.K; methodology, B.K. and V.D; investigation, A.D.L; formal analysis, A.D.L.; writing—original draft preparation, A.D.L., V.D., and G.O.; writing—review and editing, G.O.; supervision, B.K.

Funding: This research received no external funding.

Conflicts of Interest: The authors declare no conflict of interest.

\section{References}

1. Kondolf, G. Geomorphic and environmental effects of instream gravel mining. Landsc. Urban Plan. 1994, 28, 225-243. [CrossRef]

2. Rovira, A.; Batalla, R.J.; Sala, M. Response of a river sediment budget after historical gravel mining (The lower Tordera, NE Spain). Riv. Res. Appl. 2005, 21, 829-847. [CrossRef] 
3. Lee, H.Y.; Fu, D.T.; Song, M.H. Migration of rectangular mining pit composed of uniform sediment. J. Hydraul. Eng. 1993, 119, 64-80. [CrossRef]

4. Gill, M.A. Hydrodynamics of mining pits in erodible bed under steady flow. J. Hydraul. Eng. 1994, 120, 1337-1348. [CrossRef]

5. Cao, Z.; Pender, G. Numerical modeling of alluvial rivers subjected to interactive sediment mining and feeding. Adv. W. Resour. 2004, 27, 533-546. [CrossRef]

6. Chen, D.; Acharya, K.; Stone, M. Modeling of Gravel Mining in the Rio Salado, Arizona. In Proceedings of the World Environmental and Water Resources Congress, Honolulu, HI, USA, 12-16 May 2008. [CrossRef]

7. Chen, D.; Liu, M. One and two dimensional modeling of deep gravel mining in the Rio Salado. In Proceedings of the World Environmental and Water Resources Congress, Kansas City, MO, USA, 17-21 May 2009. [CrossRef]

8. Barman, B.; Kumar, B.; Sarma, A.K. Turbulent flow structures and geomorphic characteristics of a mining affected alluvial channel. Earth Surf. Proces. Landf. 2018, 43, 1811-1824. [CrossRef]

9. Yanmaz, A.M.; Cicekdag, O. Channel mining induced stream bed instability around bridges. In Proceedings of the Watershed Management and Operations Management, Fort Collins, CO, USA, 20-24 June 2000. [CrossRef]

10. Qi, M.; Kuai, Y.R. Pier scour under influence of headcut erosion of sand pit. J. Hydraul. Eng. 2017, 48, 791-798. [CrossRef]

11. Qi, M.; Yang, Y.; Kuai, Y.R. Study on Effect and Mechanism of Pier Scour Mitigation by Sill in Riverbed with Sand Excavation. China Railw. Sci. 2017, 38, 33-39. [CrossRef]

12. Ahmed, F.; Rajaratnam, N. Flow around bridge piers. J. Hydraul. Eng. 1998, 124, 288-300. [CrossRef]

13. Yagci, O.; Yildirim, I.; Celik, M.F.; Kitsikoudis, V.; Duran, Z.; Kirca, V.S.O. Clear water scour around a finite array of cylinders. Appl. Ocean Res. 2017, 68, 114-129. [CrossRef]

14. Zdravkovich, M.M. The effects of interference between circular cylinders in cross flow. J. Fluids Struct. 1987, 1, 239-261. [CrossRef]

15. Igarashi, T. Characteristics of the flow around two circular cylinders arranged in tandem: 1st report. Bull. JSME 1981, 24, 323-331. [CrossRef]

16. Ataie-Ashtiani, B.; Aslani-Kordkandi, A. Flow field around single and tandem piers. Flow Turbul. Combust. 2013, 90, 471-490. [CrossRef]

17. Chavan, R.; Kumar, B. Experimental investigations on flow and scour characteristics around tandem piers in sandy channel with downward seepage. J. Marine. Sci. Appl. 2017, 16, 313-322. [CrossRef]

18. Marsh, N.A.; Western, A.W.; Grayson, R.B. Comparison of methods for predicting incipient motion for sand beds. J. Hydraul. Eng. 2004, 130, 616-621. [CrossRef]

19. Ataie-Ashtiani, B.; Beheshti, A.A. Experimental investigation of clear-water local scour at pile groups. J. Hydraul. Eng. 2006, 132, 1100-1104. [CrossRef]

20. Wu, W.; Wang, S.S.Y. Simulation of morphological evaluation near sediment mining pits using 1-D mixed regime flow and sediment transport model. In Proceedings of the World Environmental and Water Resources Congress, Honolulu, HI, USA, 12-16 May 2008. [CrossRef]

21. Muzzammil, M.; Gangadhariah, T. The mean characteristics of horseshoe vortex at a cylindrical pier. J. Hydraul. Res. 2003, 41, 285-297. [CrossRef]

22. Chiew, Y.; Melville, B. Local scour around bridge piers. J. Hydraul. Res. 1987, 25, 15-26. [CrossRef]

23. Kumar, V.; Ranga Raju, G.; Vittal, N. Reduction of local scour around bridge piers using slots and collars. J. Hydraul. Eng. 1999, 125, 1302-1305. [CrossRef]

24. Zeng, C.; Li, C.W. Measurements and modeling of open-channel flows with finite semi-rigid vegetation patches. Environ. Fluid Mech. 2014, 14, 113-134. [CrossRef]

25. Goring, D.G.; Nikora, V. Despiking acoustic Doppler velocimeter data. J. Hydraul. Eng. 2002, 128, 117-126. [CrossRef]

26. Deshpande, V.; Kumar, B. Turbulent flow structures in alluvial channels with curved cross-sections under conditions of downward seepage. Earth Surf. Proces. Landf. 2016, 41, 1073-1087. [CrossRef]

27. Melville, B.W. Local Scour at Bridge Site. Ph.D Thesis, University of Auckland, Auckland, New Zealand, 1975. Available online: https://researchspace.auckland.ac.nz/handle/2292/2537 (accessed on 7 March 2019).

28. Kumar, A.; Kothyari, U.C. Three-dimensional flow characteristics within the scour hole around circular uniform and compound piers. J. Hydraul. Eng. 2012, 138, 420-429. [CrossRef] 
29. Soulsby, R.L.; Dyer, K.R. The form of the near-bed velocity profile in a tidally accelerating flow. J. Geophys. Res. 1981, 86, 8067-8074. [CrossRef]

30. Stapleton, K.R.; Huntley, D.A. Seabed stress determinations using the inertial dissipation method and the turbulent kinetic energy method. Earth Surf. Proces. Landf. 1995, 20, 807-815. [CrossRef]

31. Singh, A.; Lanzoni, S.; Wilcock, P.R.; Foufoula-Georgiou, E. Multiscale statistical characterization of migrating bed forms in gravel and sand bed rivers. W. Resour. Res. 2011, 47, W12526. [CrossRef]

32. Sharma, A.; Chavan, R.; Kumar, B. Multi-scale statistical characterization of migrating pier scour depth in non-uniform sand bed channel. Int. J. River Basin Manag. 2017, 15, 265-276. [CrossRef]

33. Mallat, S. A Wavelet Tour in Signal. Processing, 3rd ed.; Academic Press: Burlington, MA, USA, 1998; pp. 409-416.

34. Kumar, P.; Foufoula-Georgiou, E. Wavelet analysis for geophysical applications. Rev. Geophys. 1997, 35, 385-412. [CrossRef]

(C) 2019 by the authors. Licensee MDPI, Basel, Switzerland. This article is an open access article distributed under the terms and conditions of the Creative Commons Attribution (CC BY) license (http://creativecommons.org/licenses/by/4.0/). 